\title{
Effectiveness of An Educational Program on Knowledge and Practices Regarding Care of Central Venous Catheters among Dialysis Nurses
}

\author{
Naglaa M. Abdo ${ }^{1,2}$, Moustapha A. Ramadan ${ }^{1,3}$, Madiha M. Tosson ${ }^{4,5}$ Mariam A. Al-Fadhli ${ }^{1}$ \\ ${ }^{1}$ Infection Control Directorate, Ministry of Health, Kuwait. ${ }^{2}$ Community, Environmental and \\ Occupational Medicine Department, Faculty of Medicine, Zagazig University, Zagazig, Egypt. \\ ${ }^{3}$ Community Medicine Department, Faculty of Medicine, Alexandria University, Alexandria, \\ Egypt. ${ }^{4}$ Obstetrics and Gynecology Department, Faculty of Nursing, Assiut University. ${ }^{5}$ \\ Farwaniya Hospital, Ministry of Health, Kuwait
}

Received: October, 2018 Accepted: December, 2018

\begin{abstract}
Background: Educational activities are the main pillar for prevention of central venous catheters (CVCs) related complications and a cornerstone in raising awareness among healthcare workers (HCWs). Objective: To assess knowledge and practice of nurses of Farwaniya hospital hemodialysis (HD) unit regarding care, maintenance and prevention of catheter related bloodstream infections (CRBSIs) of CVCs before and after application of an educational program. Method: An educational intervention pre-test/post-test study that was carried out over 7 months period among HD nurses of Farwaniya hospital. Knowledge and practice towards care, maintenance and prevention of CRBSIs were assessed using a questionnaire and observation checklists in the pre- and post-intervention phases. Lectures, demonstration sessions and bedside training were applied during the intervention phase. Results: The correct knowledge items regarding care and maintenance of CVCs and prevention of CRBSIs ranged from $31 \%$ to $100 \%$ and practice items ranged from $0 \%$ to $100 \%$ at the pre-intervention phase. Significant improvement in all aspects and the total mean scores of the knowledge $(10.75 \pm 2.59$ to $13.43 \pm 1.87, \mathrm{p}<0.001)$ and practice $(23.72 \pm 1.62$ to $26.28 \pm 1.40, \mathrm{p}<0.001)$ regarding care and maintenance of CVCs was observed among the participants in the post intervention phase after implementation of the educational program. Conclusion: The implemented educational intervention program improved nurses' knowledge and practice about CVCs maintenance and care of dialysis patient. Provision of continuous and regular bed side training is a good alternative for those who cannot attend the prescheduled formal training.
\end{abstract}

Keywords: Knowledge; practice; dialysis; education; bedside training, patient safety.

Corresponding author: Naglaa M. Abdo Nagla_abdo@hotmail.com Ped_com20002001@yahoo.com

\section{Introduction}

Central venous catheters (CVCs) are a necessary component of hemodialysis (HD) care. They are present in about $43 \%$ to $73 \%$ of $\mathrm{HD}$ patients. ${ }^{1}$ Nevertheless complications associated with CVCs use are known to affect not only patient morbidity and mortality, but also have other drawbacks as increase in medical treatment costs and length of hospital stay. $^{2}$

The HD nursing staff work closely with patients providing continuous care. They are responsible to educate patients about various aspects of medical care and keep 
themselves updated. ${ }^{3}$ They are also responsible for adopting appropriate CVCs maintenance and care techniques. This has definitely an important effect in the outcome associated with the use of these devices. $^{4}$ Additionally nurses are the frontlines for any corrective measures if complications happened. ${ }^{4-5}$

Research efforts are focusing on identifying strategies to prevent/minimize the risk of the most common catheterrelated complications: thrombotic occlusion and infections. ${ }^{6}$ An important strategy to prevent and control the complications related to the CVCs is to increase health professionals' awareness on the updated evidence based practices through continuous education. ${ }^{7}$

This means that healthcare institutions should periodically review vascular access care protocols, educational strategies, and professional practices. $^{8}$ In this sense, the successful implementation of these actions, as well as the process of quality improvement as a whole, requires the engagement and commitment of the entire hospital staff. ${ }^{7-10}$

Compulsory implementation of education and training programs of CVCs evidence based protocols may result in an important decrease in the medical treatment cost and patient morbidity related to CVCs complications. ${ }^{9-11}$ There is increasing attention and efforts by Farwaniya General Hospital in Kuwait for developing effective tools and strategies to improve HD patient care and safety. Obtaining information about the level of awareness and practice of healthcare workers (HCWs) about CVCs care in HD patient is the initial step in formulating education programs for care of such patients. Therefore, this study is conducted in order to assess knowledge and practice of nurses of Farwaniya Hospital HD unit regarding care, maintenance and prevention of
CRBSIs of CVCs before and after application of an educational program.

\section{Method}

Design: This study was an educational intervention pre-test/post-test study that was carried out from May to November 2017.

Setting: HD unit of Farwaniya General Hospital, Kuwait. There were 69 HD machine. This unit provide free HD for 208 patients per month who are residing in Farwaniya governorate.

Subjects (Study Population): Nurses working in the HD unit of Farwaniya Hospital during the period of the study. There were ninety two nurses working over three working shifts. Each shift is 4 hours. Exclusion criteria: Nurses with work experience less than six months.

Sampling methods and Sample Size: Convenience sampling method by including all nurses who were working in HD unit for at least six months was used.

Data collection tools: The following tools were used to collect the required data:

1- A pre-constructed self-administered questionnaire that was developed by the researchers after reviewing literatures and centers for disease control and prevention (CDC) guidelines. $^{12}$ The questionnaire composed of the following parts: Part 1 included demographic data of the studied participants; age, gender, level of academic qualification, infection control training course and years of experience. Part 2 consisted of 18 multiple choice questions about knowledge regarding care, maintenance, complications of CVCs, risk factors and prevention CRBSIs.

Each question has only one correct answer that was scored ' 1 ' while the wrong answer was scored ' 0 '. Summation and percentage of the score of the correct answers were calculated in each knowledge item for all participants. The 
reliability of the questionnaire was measured by calculating Cronbach's alpha coefficient which was 0.87 .

2- Observational checklists: CDC observation checklists for dressing of the CVCs, connection and disconnection of CVCs to dialysis machine ${ }^{13}$ were used for assessing the nurses practice towards care and maintenance of HD patients with CVCs. Checklist items were categorized into the following main 8 items; hand hygiene before and after care, aseptic technique, ointment use for exit site care, scrubbing hubs (terminal ends) of CVCs with antiseptics, applying skin antiseptics, allowing antiseptics to dry and proper gloves use. The correct practice for each item was given score ' 1 ' and the incorrect practice was given score ' 0 '. Summation of the score of each item was done for all the participants, and the percentage of correct practice for each item was calculated.

A cut-off point at $60 \%$ was used to classify knowledge and practices of the participants independently as satisfactory or unsatisfactory.

Pilot study was conducted on 10 nurses to assess the clarity, feasibility, and time needed to fill the questionnaire and to deliver the educational sessions. The necessary modifications were done according to nurses' responses in the pilot study. The time needed for delivering the theoretical and practical sessions was $4 \mathrm{~h}$. Nurses involved in the pilot study were excluded from the study.

The study was conducted through four phases. PHASE I - pre-intervention that included the following: (1) Assessing knowledge of the nurses using the prepared self-administered questionnaire (pre-test). (2) Assessing nurses practice: The nurses' practice was observed during connection, disconnection of the patient CVCs to dialysis machines, dressing of
CVCs using the observation checklists. The observation was made by two trained infection control nurses. These two nurses were trained for two week, after which they were assessed for several practice observational sessions, compared to each other and corrected in order to avoid the inter-rater discrepancy.

Twelve visits were conducted by the trained infection control nurses over one month; four visits for each working shift. Repetition of the observation of any single nurse was avoided.

PHASE II - intervention included the following: (1) Educational sessions: Educational sessions were delivered to all participants, based on CDC and national guidelines for care and maintenance of CVCs. ${ }^{13,14}$ They included the following: A- Lectures were conducted over $1 \mathrm{~h} /$ day for 2 successive days per week over three weeks, to cover all participants in all work shifts. The sessions included the theoretical information about care, maintenance, complications of CVCs, risk factors and prevention CRBSIs. BDemonstration sessions were conducted over $2 \mathrm{~h}$ /day once weekly over three weeks. These sessions included the practical aspect of performing connection and disconnection of CVCs to dialysis machines in addition to dressing of CVCs. The educational materials included videos, posters, demonstration models and power point presentations.

(2) Bed side training and guidance: Practical bed side training and guidance for the different aspects of CVCs maintenance and care was delivered to all the participants during their work shifts by the researchers. A total of nine visits were conducted over two weeks; three visits to each working shift.

PHASE III - washout period for two months during which no education or training was delivered. 
PHASE IV- post-intervention included the following: (1) Assessing the participants knowledge regarding using the same questionnaire of phase I (posttest) (2) Assessing the practice of the participants using the same method and checklists of phase I

\section{Data management:}

Data was coded, entered and analyzed by the SPSS program version 20, qualitative data was presented as frequency and percentage while quantitative data was presented as mean and standard deviation. Mc-Nemar test was used for comparing qualitative data. Paired t test was used for comparing quantitative data. Statistical significance was set at $\mathrm{p}<0.05$.

\section{Ethical considerations:}

Ministry of Health Joint Committee for the Protection of Human Subjects in Research official approval was obtained. All nurses of the HD unit were invited for voluntary participation in the study. Informed written consent was obtained from all participants in the study after explaining the objectives and the importance of the study. Participants were assured about their right to withdraw from the study at any time, and that their responses would be kept anonymous and confidential.

\section{Results:}

Table (1) shows that the highest percentages of the participants under the study were females $(60.9 \%)$, those with basic diploma in general nursing $(56.5 \%)$, and with working experience between 6-10 years $(52.2 \%)$. One third of the participants $(30.4 \%)$ received previous infection control training. The mean age was $35.73 \pm 4.66$ years.

\section{Table (1): Socio-Demographic Characteristics of the Participants}

\begin{tabular}{lr}
\hline Characteristics & Frequency $\%$ \\
\hline Age & $9(13)$ \\
$25-30$ & $35(50.7)$ \\
$31-35$ & $14(20.3)$ \\
$36-40$ & $11(15.9)$ \\
$41-$ & $35.73 \pm 4.66$ \\
Mean \pm SD & $27(39.1)$ \\
\hline Gender & $42(60.9)$ \\
Males & $39(56.5)$ \\
Females & \\
\hline Level of Academic Qualification \\
Basic Diploma & in \\
General Nursing & $30(43.5)$ \\
BScN & $33(47.8)$ \\
\hline Experience in years & $36(52.2)$ \\
\hline 1-5 & \\
6-10 & $21(30.4)$ \\
\hline Previous & infection control training \\
\multicolumn{2}{l}{} \\
\hline Yes & $48(69.6)$ \\
\hline No & $69 *$ \\
\hline Total &
\end{tabular}

$* 13$ of the participants were dropped from the sample (on vacation, resigned)

Table (2) shows statistical significant improvement in all aspects of correct knowledge items of the participants ( $p<$ 0.05) except for "applying skin antiseptics" $(p>0.05)$ in the postintervention phase. Moreover almost all the participants' practice items improved significantly in the post intervention phase after implementation of the educational program $(p<0.05)$.

Table (3) shows statistically significant improvement the mean correct knowledge and practices scores of the participants regarding maintenance, care of CVCs and prevention of CRBSIs after implementation of the educational program $(\mathrm{p}<0.001)$. 
Table (2): Comparison of Dialysis Nurses' Knowledge and Practice before and after The Intervention

\begin{tabular}{|c|c|c|c|}
\hline Items & $\begin{array}{c}\text { Before } \\
\text { intervention } \\
(69)(\%)\end{array}$ & $\begin{array}{c}\text { After } \\
\text { intervention } \\
(69)(\%)\end{array}$ & $P$ value* \\
\hline $\begin{array}{l}\text { Correct knowledge: } \\
\text { - Risk factors for CRBSIs } \\
\text { - Complications of CVCs } \\
\text { - Prevention CRBSIs } \\
\text { - Catheter care and maintenance: } \\
\text { Hand hygiene } \\
\text { Dressing changes } \\
\text { Hub scrubbing } \\
\text { Applying skin antiseptics } \\
\text { Allowing antiseptics to dry } \\
\text { Applying ointment } \\
\text { Gloves use }\end{array}$ & $\begin{array}{r}35(50.7) \\
48(69.6) \\
35(50.7) \\
63(91.3) \\
27(39.1) \\
22(31.9) \\
69(100.0)\end{array}$ & $\begin{array}{r}47(68.1) \\
56(81.2) \\
47(68.1) \\
64(92.8) \\
42(60.9) \\
40(58) \\
69(100.0)\end{array}$ & $\begin{array}{l}<0.001 \\
<0.001 \\
<0.001 \\
>0.05 \\
<0.001 \\
<0.001 \\
\ldots \ldots\end{array}$ \\
\hline $\begin{array}{l}\text { Satisfactory knowledge score } \\
(>60 \%)\end{array}$ & $30(43.5)$ & $51(73.9)$ & $<0.001$ \\
\hline $\begin{array}{l}\text { Correct practice: } \\
\text { - Hand hygiene before the } \\
\text { procedure } \\
\text { - Aseptic technique } \\
\text { - Scrubbing hub with antiseptic } \\
\text { - Applying skin antiseptic } \\
\text { - Allowing antiseptics to dry } \\
\text { - Gloves use } \\
\text { - Ointment use } \\
\text { - Hand hygiene after the } \\
\text { procedure } \\
\text { - Satisfactory practice score } \\
\text { (>60\%) }\end{array}$ & $\begin{array}{r}15(30) \\
29(58) \\
33(66) \\
48(96) \\
0(0.00) \\
50(100) \\
8(16) \\
30(60) \\
23(46)\end{array}$ & $\begin{array}{r}34(68) \\
40(80) \\
43(86) \\
50(100) \\
16(32) \\
50(100) \\
17(34) \\
41(82)\end{array}$ & $\begin{array}{l}<0.001 \\
<0.05 \\
<0.05 \\
---- \\
---- \\
--- \\
<0.05 \\
<0.05 \\
<0.01\end{array}$ \\
\hline
\end{tabular}

Table (3): Mean Score of Knowledge and Practice of The Participants Regarding Care, Maintenance of CVCs and Prevention of Sepsis.

\begin{tabular}{llccc}
\hline & $\begin{array}{c}\text { Before } \\
\text { Intervention } \\
\text { Mean } \pm \text { SD }\end{array}$ & $\begin{array}{c}\text { After } \\
\text { Intervention } \\
\text { Mean } \pm \text { SD }\end{array}$ & $\begin{array}{c}\text { Test of } \\
\text { significance* }\end{array}$ & $\begin{array}{c}\text { P } \\
\text { value }\end{array}$ \\
\hline Knowledge score & $10.75 \pm 2.59$ & $13.43 \pm 1.87$ & 7.76 & $<0.001$ \\
\hline Practice score & $23.72 \pm 1.62$ & $26.28 \pm 1.40$ & 9.09 & $<0.001$ \\
\hline *Paired t test & & & &
\end{tabular}




\section{Discussion}

Studying the main socio-demographic characteristics of the participants showed that our participants who hold bachelor degree in nursing represented $(43.5 \%)$, which was similar to what found by El-Sol et al (43.2.\%) ${ }^{15}$ among intensive care unit (ICU) nurses and higher than participants in a study conducted in pediatric HD center in Egypt and another study at Italian oncology center $(27 \%$ and $29.5 \%$ respectively). ${ }^{16,17}$

On the other hand nurses who had experience for 6 years or more among our participants represented a lower percentage $(52.2 \%)$ in comparison to what was described by El-Sol et al and Esposito and his colleagues among ICU and oncology nurses ( $75 \%$ and $60.5 \%$ respectively). ${ }^{15,17}$

Furthermore, we found that $(69.6 \%)$ of the participating nurses did not receive previous infection control training on CVCs maintenance and care. This finding is close to what was revealed by Bayoumi et al and Nemr et al among their participants at a pediatric HD center $(75 \%)$ and university hospital ICU (76.19\%). ${ }^{16,18}$ Training in most of HD centers was found to rely on senior nurses who instruct and educate new staff members on protocols of CVCs care. ${ }^{19}$

Although a formal training about updated infection control guidelines for CVCs maintenance and care is conducted every year by the Farwaniya hospital infection control team for the HD nurses, however only few number of nurses attend. Nurses at HD centers are usually busy and cannot leave the patient area for a longer period this is in addition to that infection control training sessions are always conducted during morning shifts. This highlights the importance of the bedside training in order to cover all nurses working at the alternating shifts.
The knowledge level and evidence based practices of $\mathrm{HCWs}$ regarding care and maintenance of different elements of CVCs in different settings has been

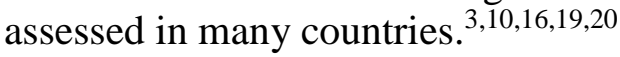

The studied elements related to care and maintenance of CVCs vary from study to another based on the study design (interventional, descriptive), population, aspects and settings. These variation does not create discrepancy in comparison, on the contrary it enriches the information gained from these researches and elucidate new elements for future studies.

Our study demonstrated that $(43.5 \%)$ of participants had a satisfactory level of knowledge regarding maintenance and care of CVCs and prevention of CRBSIs at the pre-intervention stage increased to $(73.9 \%)$ post interventional. Our participants correct knowledge items ranged from (31\% to $100 \%)$ in the pre-intervention phase and raised at the post-intervention to range from (58\% to $100 \%$ ).

While another study conducted in pediatric HD unit revealed that the participants' correct knowledge ranged from $2.5 \%$ to $47.5 \%$ at the pre- intervention phase and changed to be $90 \%$ to $100 \%$ in the post education phase. ${ }^{(16)}$ Other cross sectional studies showed different knowledge ranges depending on the units; El Nemr et al revealed a knowledge range among the studied elements ranging from $9.1 \%$ to $58.3 \% .{ }^{18}$ Also Bianco et al showed that the level of knowledge among physicians and nurses from different units ranged from 43 to $72.9 \% .^{21}$

Although hand hygiene is an important element in infection control standard precautions, our study demonstrated a positive response percentage only among $42 \%$ of nurses in the pre-intervention phase which raised to $59.4 \%$ at the postintervention phase. Yet this percentage 
remained lower than what found by Shah et al with a $92 \%$ positive answers regarding hand hygiene and CVCs maintenance and care. ${ }^{22}$ This could be explained that our nurses still believe that wearing gloves is a good substitute to hand hygiene.

Regarding dressing changes, our nurses showed a comparable correct knowledge in both pre and post intervention phases (69.6\% and $81.2 \%)$ to what was found by Esposito et al (76\%) and Barbosa et al $(85 \%)$ among their responders. ${ }^{17,23}$

Our nurses at the pre-intervention phase, had a lower knowledge level regarding risk factors, and prevention of CRBSIs (42\%, and $39.1 \%$ respectively) in comparison to what Bayoumi et al revealed in their study (47.5\% for both aspects). ${ }^{16}$ Although our nurses had increased their knowledge for these studied elements to reach $(59.4 \%)$ at the post-interventional phase, yet it remained much lower than reported by Bayoumi et al (100\%). ${ }^{16}$

On the other hand at the pre-intervention phase, our nurses' knowledge for complications related to CRBSIs was higher $(63.8 \%)$ when comparing it to what shown by Bayoumi and her colleague $(37.5 \%) .{ }^{16}$ However at the post intervention Bayoumi et al displayed a better knowledge among their studied group which reached $(100 \%)$ in comparison to our nurses' knowledge $(76.8 \%)^{16}$

On the other hand, our study showed an improvement in the understanding about scrubbing the hub between the pre and post intervention phases (50.7\% and $68.1 \%)$, but this percentage remained lower when comparing to Italian and Brazilian studies (77.5\% and $90 \%$ respectively). ${ }^{17,23}$

Continuing with another element of the study, knowledge about applying skin antisepsis at catheter site in which our nurses had a great acquaintance $(91.3 \%$ at the pre intervention phase and $92.8 \%$ at the post intervention phase) which was higher to what showed by Esposito et al (20\%), Barbosa et al $(85 \%)$ and Koutzavekiaris et al (69.4\%). ${ }^{17,23,24}$ However, our nurses did not have a good knowledge about allowing the antisepsis to dry before any further intervention. While the knowledge improved from $(31.9 \%$ to $60.9 \%)$ nevertheless it remained lower to what found by Koutzavekiaris et al $(83.3 \%){ }^{24}$

As for the antibiotic ointment application our participants had responded to this element positively with $(31.9 \%)$ at the pre intervention stage and (58\%) at the post intervention stage. Yet these percentage remained lower to what discussed by Bayoumi et al in their interventional study (42\% at the pre interventional phase and $95 \%$ at the post-interventional). ${ }^{16}$

Regarding the last element studied concerning the knowledge was the proper use gloves showed a $100 \%$ compliance in both study phases. While Koutzavekiaris and his colleagues revealed a slightly lower percentage in their study $(95.8 \%){ }^{24}$

The overall participant nurses' practices concerning maintenance, care of CVCs and prevention of CRBSIs showed a significant increase from $46 \%$ in the pre-intervention phase to $72 \%$ at the post intervention phase. The correct practice elements ranged from $0 \%$ to $100 \%$ at the preintervention phase and increased after the intervention to range from $32 \%$ to $100 \%$. This finding was consistent with Labeau et al who expected such a wide variation of the practices among critical care nurses after conducting their study to assess their knowledge regarding guidelines for prevention of catheter related bloodstream infection in 22 European countries. ${ }^{25}$

Regarding hand hygiene practice, our nurses showed a better hand hygiene compliance rate at the pre-intervention phase $(30 \%)$ in comparison to similar studies among nurses at pediatric HD (0\%) and ICU $(22.5 \%)$ units. $^{16,18}$ At the post 
intervention phase, our nurses hand hygiene compliance rate increased significantly to reach $(68 \%)$ which was higher than what described by Bayoumi et al and Koutzavekiaris et al among their participants in the post intervention phase $\left(52.5 \%, 66.2 \%\right.$ respectively). ${ }^{16,24}$

All observations showed that our nurses were adherent to wearing gloves before any manipulation at the CVCs. This rate was higher than what found by other researchers in different settings and countries; in two studies in Egypt (70\% and $45 \%),{ }^{16,18}$ Italy $(93.8 \%)^{17}$ and Iran $(96.4 \%){ }^{26}$

Though the adherence of our participants to aseptic technique increased significantly from $(58 \%)$ in the pre-intervention to (80\%) after the intervention, but it remained lower than the adherence found among the nurses at HD center in Iran $(91.8 \%){ }^{26}$

A significant increase in the compliance concerning disinfecting the connectors before usage was observed among our nurses. The rate increased from $(66 \%)$ in the pre-intervention to $(86 \%)$ at the post intervention phase. This rate was higher than what observed by researchers at an oncology center in Italy $(27 \%){ }^{17}$

The participant nurses showed almost a full compliance with applying skin antiseptic at vascular access, (96\% at preintervention phase and $100 \%$ at the post intervention phase). This rate was higher than to what reported by Bayoumi et al 6 months after the intervention $(75 \%)^{16}$ and Esposito et al (87.8\%). ${ }^{17}$

However only about one third (32\%) of our observation among the nurses at the post-interventional phase let antiseptic to dry at vascular access, which was similar to what found by Esposito et al (33.3\%). ${ }^{17}$ Further emphasis on educating nurses on the value of allowing antiseptics to dry before any intervention will decrease the chance of infection. ${ }^{27}$
Regarding the application of antibiotic ointment, our nurses showed increase in their compliance practice from $(16 \%)$ in the pre-intervention to (34\%) in the post intervention. Available studies on the effect of education among HCWs concerning the application of local antibiotics are scarce. However studies available showed the effect of antibiotic use by various forms (local, systemic) in the reduction of CRBSI. Researchers conducted systemic review of these studies were unable to recommend the routine use of antibiotics for several factors and suggested the use of antibiotics should always rely on local infection rate and practices. $^{28,29}$

Our investigation showed significant improvement in the mean correct knowledge (10.75 \pm 2.59 to $13.43 \pm 1.87)$ and practice scores $(23.72 \pm 1.62$ to $26.28 \pm 1.40$ ) of the participants regarding care, maintenance of CVCs and prevention of CRBSIs in the post intervention phase after application our educational program. This finding is consistent with other interventional studies in different settings and different countries. A study conducted by Deshmukh et al among cancer unit nurses in Nursing Sciences Institute, India showed increase in the mean scores of knowledge and practices regarding venous access device care from 14.6 to 21.3 and 15.4 to 19.6 respectively in the post-test after application structured education. ${ }^{3}$

El-Sol and her colleagues who conducted a quasi-experimental study to evaluate the effect of designed teaching module regarding prevention of central line associated blood stream infection among ICU nurses found that mean score of knowledge increased from the preintervention $5.09 \pm 0.76$ to $9.66 \pm 0.56$ four weeks later. Same for the practice, they revealed improvement in the mean practice score from $5.91 \pm 0.93$ to $9.96 \pm 0.66$ at the post training phase. ${ }^{15}$ 
The outcome of current study confirms the importance of training and education of healthcare workers in improving their knowledge and practices regarding CVCs care and maintenance in addition to reduction of CRBSIs. ${ }^{3,11,30,31}$ These encouraging results might have been due to the use of different educational methods, including lectures and demonstration method, which were supported by audiovisual tools. Demonstration method is an explanation of a process which enables the learner to acquire knowledge by carful observation which in turn enforced the delivered verbal knowledge. ${ }^{(3)}$ Moreover the direct guidance and the immediate corrective feedbacks during bedside teaching are helpful. ${ }^{32}$

Limitation of the study:We could not assess the projection of the improved knowledge and practice of the participants on the change of CRBSIs rate as data required for the rate calculation are not readily available or calculated at our HD unit. Moreover, patients who develop CRBSIs may not present to the unit. This makes the development of a surveillance system in the future mandatory to properly evaluate the effectiveness of maintenance and care of CVCs.

\section{Conclusion and Recommendations:}

Our educational intervention program improved nurses' knowledge and practice about CVCs maintenance and care of dialysis patient. Provision of continuous and regular bed side training is a good alternative for those who cannot attend the prescheduled formal training.

\section{Acknowledgments}

The researchers would like to thank all the participants for their participation in the study. We are also very grateful to the infection control nurses who supported and helped us.

\section{References:}

1. Hussein W, Mohammed H, Browne L, Plant L, Stack AG. Prevalence and correlates of central venous catheter use among haemodialysis patients in the Irish health system - a national study. BMC Nephrol. 2018; 19: 76.

2. Leistner R1, Hirsemann E, Bloch A, Gastmeier $\mathrm{P}$, Geffers C. Costs and prolonged length of stay of central venous catheter-associated bloodstream infections (CVC BSI): a matched prospective cohort study. Infection. 2014;42(1):31-6

3. Deshmukh M, Shinde M. Impact of Structured Education on Knowledge and Practice Regarding Venous Access Device Care among Nurses. IJSR. 2014; 3(5): 895-901.

4. Flodgren G, Conterno LO, Mayhew A, Omar $\mathrm{O}$, Pereira CR, Shepperd S. Interventions to improve professional adherence to guidelines for prevention of device-related infections. Cochrane Database Syst Rev. 2013; (3): Cd006559.

5. Aiken LH, Cimiotti JP, Sloane DM, Smith HL, Flynn L, Neff DF. The effects of nurse staffing and nurse education on patient deaths in hospitals with different nurse work environments. Med Care 2011;49(12):1047-53.

6. Han Z, Liang SY, Marschall J. Current strategies for the prevention and management of central line-associated bloodstream infections. Infect Drug Resist. 2010; 3: 147-163.

7. Mendonça KM, Neves HCC, Barbosa DFS, Souza ACS, Tipple AFV, Prado MA. Nursing care in the prevention and control of catheter-related bloodstream infections. UERJ. 2011;19(2):330-3.

8. Jardim JM, Lacerda RA, Soares NJD, Nunes BK. Evaluation of practices for the prevention and control of bloodstream infections in a government hospital. USP. 2013;47(1):38-45.

9. Bonz J, Wong A, Evans L. Implementation of a Hospital Mandated Central Venous Catheter (CVC) Training Program. Ann Vasc Med 2017; 4(6): 1074.

10.Perin DC, Erdmann AL, Higashi GDC, Dal Sasso GTM. Evidence-based measures to prevent central line-associated bloodstream infections: a systematic review. Rev Lat Am Enfermagem. 2016; 24: e2787.

11.Kadium MJ. Improving nurses' knowledge to reduce catheter- related bloodstream infection in hemodialysis unit. Walden Dissertations and Doctoral Studies, Walden University. 2015 
12.Centers for disease control and prevention. Guidelines for the Prevention of Intravascular Catheter-Related Infections (2011). https://www.cdc.gov/infectioncontrol/guidelin es/pdf/bsi/bsi-guidelines-H.pdf (Accessed 13 April 2017).

13.Centers for disease control and prevention. Dialysis safety. Infection prevention tools. Audit tools and checklists. https://www.cdc.gov/dialysis/preventiontools/audit-tools.html (last access 12/12/2018). 14. Infection Control Directorate, Ministry of Health, Kuwait. Recommended Practices for Prevention and Control of Infections in Dialysis Settings available at:

15.http://www.icdkwt.com/pdf/policiesandgui delines/InfectionPreventionandControl/Recom mended-Practices-for-Prevention-and-Controlof-Infections-in-Dialysis-Settings.pdf. (Last access 15 May 2017).

16.El-Sol A, Badawy A. The effect of a designed teaching module regarding prevention of central-line associated blood stream infection on ICU nurses' knowledge and practice. AJNS. 2017; 6(1) 11-18.

17.Bayoumi M, Mahmoud N. Effect of education program on nurses' knowledge and practice regarding care of central venous line in pediatric hemodialysis: evidence-based practice guidelines. Egyptian Nursing Journal. 2017; 14:87-99.

18.Esposito MR, Guillari A, Angelillo IF. Knowledge, attitudes, and practice on the prevention of central line-associated bloodstream infections among nurses in oncological care: A cross-sectional study in an area of southern Italy. PLoS ONE. 2017; 12(6): $\mathrm{e} 0180473$.

19.El Nemr W, Fahmy H, Abed El Razek G, Abed El Salam N. An interventional study to decrease central venous catheter related blood stream infection in intensive care units at Zagazig university hospital. ZUMJ. 2013; 19 (6): 492-507.

20.Abdelsatir S. Evaluation of nurses' awareness and practice of hemodialysis access care in Khartoum state, Sudan. Arab J Nephrol Transplant. 2013;6(2):119-21.

21. Guembe M, Bustinza A, Sanchez Luna M, Carrillo-Alvarez A, Perez Sheriff V, Bouza
E. Guidelines for preventing catheter infection: assessment of knowledge and practice among paediatric and neonatal intensive care healthcare workers. J Hosp Infect. 2012; 81:123-7.

22. Bianco A, Coscarelli P, Nobile CGA, Pileggi C, Pavia M. The reduction of risk in central line-associated bloodstream infections: Knowledge, attitudes, and evidence-based practices in health care workers. AJIC. 2013; 41(2):107-112.

23.Shah M, Qasim M, Fazalhadi, Zeeshanwahab, Tajuddin and Abdul shakoor. Practice of Nursing Care for Central Venous Catheter among ICUs Nurses in Private Tertiary Care Hospital Peshawar, KP. JOJ Nurse Health Care. 2017; 2(2): 555585.

24.Barbosa CV, Canhestro MR, Cauto BRGM, Guimarães GL, Mendoza IYQ, Goveia VR. Knowledge of the nursing team on care with central venous catheter. J Nurs UFPE on line, Recife. 2017; 11(11):4343-50.

25.Koutzavekiaris I, Vouloumanou E, Gourni M, Rafailidis P, Michalopoulos A, Falgas ME. Knowledge and practices regarding prevention of infections associated with central venous catheters: A survey of intensive care unit medical and nursing staff. Am J Infect Control 2011;39: 542-7. 26.Labeau SO, Vandijck DM, Rello J, Adam S, Rosa A, Wenisch C, Bäckman C, Agbaht K, Csomos A, Seha M, Dimopoulos G, Vandewoude $\mathrm{KH}$, Blot SI; EVIDENCE Study Investigators. Centers for Disease Control and Prevention guidelines for preventing central venous catheterrelated infection: results of a knowledge test among 3405 European intensive care nurses. Crit Care Med 2009;37:320-3.

27.Adib-Hajbaghery M, Molavizadeh N, Alavi NM. Quality of care of vascular access in hemodialysis patients in a hemodialysis center in Iran. J Vasc Nurs 2012;30:24-28.

28. Hadaway L. 5 Steps to preventing catheterrelated bloodstream infections. LPN. 2006;2 (5):50-55.

29.Canadian Agency for Drugs and Technologies in Health (CADTH). Antimicrobial Ointments for Patients Undergoing Hemodialysis: A Review of Evidence-Based Guidelines. Rapid Response Report with Critical appraisal 2013. https://www.cadth.ca/antimicrobial-ointmentspatients-undergoing-hemodialysis-review- 
evidence-based-guidelines. (Last access 18/12/2018).

30.Miller LM, Clark E, Dipchand C, Hiremath S, Kappel J, Kiaii M, Lok C, Luscombe R, Moist L, Oliver M, MacRae J and on behalf of the Canadian Society of Nephrology Vascular Access Work Group. Hemodialysis Tunneled Catheter-Related Infections. Can J Kidney Health Dis. 2016; 3 : 1-11.
31.Cooper K, Frampton G, Harris P, Jones J, Cooper T, Graves N, Cuthbertsof BH. Are educational interventions tk prevent catheterrelated bloodstream infections in intensive care unit cost-effective? J Hosp Infect. 2014; 86(1): 4752.

32.Kim JS, Holtom P, Vigen C. Reduction of catheter-related bloodstream infections using a central venous line bundle: Epidemiologic and economic consequences. Am J Infect Control. 2011;39(8):640-64.

33. Sherertz, R J, Ely EW, Westbrook DM, Gledhill KS, Streed SA, Kiger B, Haponik EF. Education of physicians-in-training can decrease the risk for vascular catheter infection. Ann of Intern Med. 2000; 18;132(8):641-8. 